\title{
Adapting ACT for jail diversion: current evidence and needed research Joseph Morrissey
}

\author{
Address: University of North Carolina, 725 MLK Jr Boulevard, Chapel Hill, North Carolina 27599-7590, USA \\ from WPA Thematic Conference. Coercive Treatment in Psychiatry: A Comprehensive Review \\ Dresden, Germany. 6-8 June 2007 \\ Published: 19 December 2007 \\ BMC Psychiatry 2007, 7(Suppl I):S36 doi:10.1 I86/I47I-244X-7-SI-S36
}

This abstract is available from: http://www.biomedcentral.com//47I-244X/7/SI/S36

(C) 2007 Morrissey; licensee BioMed Central Ltd.

\section{Background}

Assertive community treatment (ACT) has been found to be effective in reducing hospitalization of mentally ill consumers in a large number of studies. Yet, its role in keeping people out of jail is less well documented. This presentation assesses available evidence concerning the effectiveness of forensic ACT (FACT) in reducing arrests and jail detentions.

\section{Methods}

The published literature since 1985 using randomized controlled studies of ACT was reviewed. In addition, site visits were made to several sites around the US to identify the range of ACT accommodations made.

\section{Results}

In one review [1], 7 of 10 randomized trials found that ACT was no more effective in reducing arrests and jail stays than usual care and in one trial it was less effective. Another recent trial [2] found that receipt of ACT was not a significant predictor of a range of criminal justice outcomes including offenses, arrests, incarcerations, or court summons. Current FACT programs strip away some highfidelity components of ACT (such as $24 \mathrm{~h}$ availability, daily team meetings, an employment specialist) and add new elements not found in typical ACT teams (such as a probation or parole officer on the team, recruitment from criminal justice settings, supervised residential treatment component for high risk consumers with substance abuse comorbidities.) Current evidence for the effectiveness of these FACT models is sparse. Some uncontrolled studies suggest positive effects, but the one randomized trial reported to date found no differences between a FACT-like intervention and usual care.

\section{Conclusion}

ACT alone or its FACT adaptations do not appear to be able to keep mentally ill offenders out of jail. Interventions are also needed that target criminal behavior and life-styles. Further research on the effectiveness of these FACT-plus models can grow the evidence base for how to reduce the criminalization of mental illness.

\section{References}

I. Bond GR, Drake RE, Mueser KT, Latimer E: Assertive community treatment: critical ingredients and impact on patients. Dis Manag Health Outcomes 200I, 9:14I-I59.

2. Calsyn RJ, Yonker RD, Lemming MR, Morse GA, Klinkenberg WD: Impact of assertive community treatment and client characteristics on criminal justice outcomes in dual disorder homeless individuals. Crim Behav Ment Health 2005, 15:236-248. 